\title{
Stochastic Prognostic Paradigm for Petrochemical Pipelines Subject to Fatigue
}

\author{
${ }^{1}$ Abdo Abou Jaoude and ${ }^{2}$ Khaled El-Tawil \\ ${ }^{1}$ Lebanese University (EDST), Hadath Campus, Lebanon and Aix-Marseille University, France \\ ${ }^{2}$ Lebanese University, Faculty of Engineering and EDST, Hadath Campus, France
}

Received 2012-12-26, Revised 2012-12-28; Accepted 2013-05-06

\begin{abstract}
The most important aim for industrialists is the prevention and the evaluation of their products state since non-predicted failure is very expensive in some cases. This can be done mainly by the evaluation of the "Remaining Useful Lifetime" (RUL) by the means of prognostic approaches compensating the inconveniences of classical maintenance strategies. A proposed analytic prognostic methodology based on damage laws, such as Paris-Erdogan's and Palmgren-Miner's laws, is developed here to determine the RUL of the system. It permits to ensure a high availability and productivity with less cost for industrial systems. To make this approach more reliable, it is essential to introduce the stochastic description. For the case of fatigue effect where damage state is growing from macro-cracks to total failure, $\mathrm{D}(\mathrm{N})$ expresses an increasing scalar damage function in terms of loading cycles $\mathrm{N}$. The RUL is estimated from a predefined threshold of damage $\mathrm{D}_{\mathrm{C}}$. Pipelines tubes, subject to fatigue effects due to pressure-depression alternation, belong to vital mechanical systems in petrochemical industries that serve to transport natural gases or liquids. The prognostic evaluation of their states increases the tubes availability while minimizing their missions cost.
\end{abstract}

Keywords: Prognostic, Analytic, Damage, Stochastic, Fatigue, Pipelines

\section{INTRODUCTION}

The last phase during each system life represents the progressive degradation period. It is important to predict, at each instant, the remaining lifetime in order to prevent expensive breakdown and to avoid catastrophic failures. Adopting preventive systematic maintenance by frequent replacement to increase the system availability is an expensive strategy (Inman et al., 2005).

The prognostic is a methodology aiming at predicting the RUL of a system in service (Vachtsevanos et al., 2006). It can be expressed in hours of functioning, in Kilometers run, or in cycles. The prognostic is defined as the ability to "predict and prevent" possible fault or system degradation before failures occurrence (Lee, 2004). Maintenance actions can be taken ahead of time if the condition of machines and systems can be effectively predicted.
Several prognostic studies are proposed and are based on abaci of degradation without any analytic form (Peysson, 2009). A prognostic methodology based on analytic laws in fracture mechanics, such as the crack propagation and the damage accumulation laws, is proposed later (Abou Jaoude et al., 2010). Whenever such analytic laws are available, this methodology seems to be interesting. A degradation indicator $\mathrm{D}$ was taken to describe the evolution from an initial micro damage till the total system failure.

In addition, by including a stochastic analysis on the previous model (Abou Jaoude et al., 2010), it becomes more precise for RUL prediction since it covers more possible realizations. This is done by considering some parameters as random variables.

Our aim is to prepare a general prognostic tool that can be capable of well predicting the RUL of a system Corresponding Author: Abdo Abou Jaoude, Lebanese University (EDST), Hadath Campus, Lebanon and Aix-Marseille University, France 
based on an analytical damage accumulation in either deterministic or stochastic context. Knowing that, the fatigue RUL can be expressed in terms of: crack length $\mathrm{a}_{\mathrm{C}}$, or critical number of loading cycles $\mathrm{N}_{\mathrm{C}}$, or material tenacity $\mathrm{K}_{\mathrm{IC}}$, from which various limit states can be written.

The life prognostic of petrochemical pipelines is vital in their domain since their availability has crucial consequences. Fatigue failure is their main failure cause due to internal pressure-depression variation along the time. Usually, three situations for these pipes exist: unburied, buried and under sea water (offshore pipes). Each one of these situations requires different physical parameters like: Corrosion, soil pressure and friction, water and atmospheric pressure.

In the present work, the prognostic study is applied to unburied pipes taking into account an analytical damage accumulation and considering two random variables which are the internal pressure $\mathrm{P}_{0}$ with Triangular distribution and the initial crack length $\mathrm{a}_{0}$ with Log-Normal distribution.

The study is organized as follows: first a detailed state of the art is elaborated, second a stochastic prognostic paradigm is proposed, third an application to petrochemical pipelines is considered, fourth the results of corresponding simulations are shown, fifth a flowchart summarizes the methodology and finally, a conclusion is presented.

\subsection{State of the Art: Stochastic Fatigue Modeling}

The science and technology of prognosis and structural health management offer the potential for significant enhancements in the safety, reliability and availability of high-value resources (Christodoulou and Larsen, 2004). This concept is based on a closed-loop process whose successful implementation depends on the integration of several multi-disciplinary elements including (Hudak et al., 2002):

- Onboard sensing of operational parameters and material damage states

- Diagnosing trends, fault conditions and underlying damage

- Predicting remaining useful life in terms of probability of failure and limits on reliable performance

- Deciding upon appropriate courses of action: whenever or not the resource is capable of performing a given mission, or alternatively, is in need of inspection, maintenance, or replacement

Considerable uncertainty exists in the usage and sensor inputs, as well as the required modeling and associated material property inputs. Consequently, there is an inherent need for the reasoning element of the prognosis system to be probabilistically-based.

In contrast, probabilistic life prediction is typically based on material property data, finite element thermal and stress analysis, pre-service inspection and in-service monitoring for defects and damage accumulation algorithms. The advantage of this approach is that it is more amenable to linkage with the underlying physical mechanisms of damage (i.e., crack nucleation and growth). Thus, the process is inherently suitable for extension into materials prognosis, a novel concept that seeks to combine information on the material damage state with mechanistically-based predictive models.

Probabilistic analyses of prognostic uncertainty were performed using a probabilistic life prediction code DARWIN (Leverant et al., 1977) as a demonstration platform. DARWIN integrates finite-element stress analysis results, fracture-mechanics-based life assessment for low-cycle fatigue, material anomaly data, probability of anomaly detection and inspection/monitoring schedules to determine the probability-of-fracture of rotor disks as a function of operating cycles. In the study on lives of turbine engines (Hudak et al., 2002), enhancements were added to the DARWIN code to enable the type of analyses required for prognosis: (1) Establishment of interface with engine sensor data; (2) Adding of the fatigue crack initiation analysis to existing fatigue crack propagation analysis; (3) Incorporates the integration of crack initiation and propagation algorithms including correlation effects between the two damage processes; (4) Adding a damage-based load filtering method to reduce computational time; (5) Capability to analyze a large number of inspections (or interrogation-up to once per flight cycle) to simulate continuous monitoring with an on-board sensor. Although DARWIN contains several probabilistic solutions methods, the analyses in reference to (Hudak et al., 2002) were performed using Monte Carlo simulation.

Other models have been proposed to describe the random behavior of fatigue crack growth in metals. In Yang and Manning (2003) stochastic model a simple second order approximation of a deterministic crack growth model is used with a random component.

For instance, with transitional loading the model parameters will vary as the fatigue damage propagates. The model parameter variability was taken into account in the data driven part of the analytical crack exceedance probability, which is the probability that the crack length will exceed a number of cycles, with the respective load 
period. To directly account for the variance in the crack growth rate, the random component is assumed to follow a Log-Normal distribution (Moreno et al., 2003).

A significant part of main pipelines are subjected to external cracking, which is a serious problem for the pipeline industry like in Russia, U.S. and Canada and others (Sergeeva and Bolotov, 1996; Jaske, 2000). Identification of external cracks is achieved using different Nondestructive Evaluation (NDE) methods. If cracks are revealed during inspection, their influence on the Remaining Useful Lifetime (RUL) of the pipeline should be assessed in order to choose what maintenance action should be used: do nothing/repair/replace.

Pipeline integrity is assessed on the assumption that some defects after In-Line Inspection (ILI) may be: still undetected; detected, but not measured; detected and measured. It is possible to update the stochastic remnant life of pipelines using the data available due to ILI.

The works of Timashev et al. (2005) describe a new practical method of updating the stochastic remaining life of pipelines with defects using the latest ILI data. It describes a comprehensive algorithm for assessing pipeline remnant life taking into account the results of holistic statistical analysis of In-Line Inspection (ILI) data. It is assumed that the pipeline segment wall has a longitudinal external crack of semi-elliptical form and is described by the J-integral. The Limit State Function (LSF) is described as the difference of the critical and current value of the J-integral. The critical crack depth is defined using the notion of fracture toughness and the Jintegral approach.

Model-based prognostic techniques rely on a dynamic model of the predicted process. This approach uses a mathematical model of the process in order to implement the physical understanding of the system into the diagnostic problem. Such models should describe both nominal and faulty behavior of the system. As a result, it is possible to explain the fault progress in time and to make End of Life (EOL) and RUL predictions. These methods involve the estimation of residuals as a deviation between the real system measurements and proposed model outputs. In the ideal case, the residuals are zero but in reality there are permanent noise and modeling errors. It is, therefore, expected that the residuals are small in the nominal working mode and larger in the presence of a failure. Once the residuals are obtained, it is possible to use some statistic representation to estimate the distribution of RUL as a function of present uncertainties and to calculate possible damage.
In this study, system modeling is considered by the physics-based prognosis derived by using physics laws and principles. Crack initiation based models must include all the available information about component and its environment (temperature, humidity, soil effects). The crack propagation models can be divided into two main groups: deterministic and stochastic. Deterministic crack propagation models, which usually describe the growth of the crack, are based on Paris (1963) law. Stochastic crack propagation involves models with random parameters which can be estimated using Monte Carlo simulations.

\subsection{Stochastic Damage Accumulation}

An analytical prognostic model recently developed (Abou Jaoude et al., 2011a; 2011b) aims at giving a useful RUL prediction tool. This model uses the physical law of Paris-Erdogan for crack propagation (Paris, 1963) and the law of Palmgren-Miner for linear damage accumulation (Miner, 1945), to estimate the residual lifetime in fatigue failure risk. It consists of the evaluation of a normalized degradation indicator D $(0 \leq$ $\mathrm{D} \leq 1$ ) in terms of load cycle numbers $\mathrm{N}$.

The fatigue failure is reached when the crack size "a" grows to a critical size $a_{C}$ with respect to Paris' law where the necessary number of cycles is the critical number $\mathrm{N}_{\mathrm{C}}$. Using Miner's cumulative damage, after each load cycle, the damage indicator $\mathrm{D}$ increases by a relative crack length increment da as indicated by the following expression Equation1 (Abou Jaoude et al., 2010):

$$
D_{i}=\frac{1}{a_{C}-a_{0}} \sum_{j=1}^{i} d a_{j}=\frac{a_{i}}{a_{C}-a_{0}}
$$

The deterministic Paris' law is given by Equation 2:

$$
\begin{aligned}
& \frac{\mathrm{da}}{\mathrm{dN}}=\mathrm{C} \cdot[\Delta \mathrm{K}(\mathrm{a})]^{\mathrm{m}} ; \\
& \Delta \mathrm{K}(\mathrm{a})=\mathrm{Y}(\mathrm{a}) \cdot \Delta \sigma \cdot \sqrt{\pi \cdot \mathrm{a}}
\end{aligned}
$$

Where:

$$
\begin{aligned}
\mathrm{a}_{0}= & \text { The initial crack length } \\
\mathrm{a}= & \text { The actual crack length } \\
\mathrm{N}= & \text { The load cycle } \\
\mathrm{C} \text { and } \mathrm{m}= & \text { The material and environment parameters }(0 \\
& <\mathrm{C}<<1) ;(2 \leq \mathrm{m} \leq 4) \text { (Lemaitre and } \\
& \text { Chaboche, } 1994) \\
\Delta \mathrm{K}(\mathrm{a})= & \text { The stress intensity factor range } \\
\mathrm{Y}(\mathrm{a})= & \text { The geometric factor function of the body } \\
& \text { dimensions } \\
\Delta \sigma \quad= & \text { The applied stress range }
\end{aligned}
$$




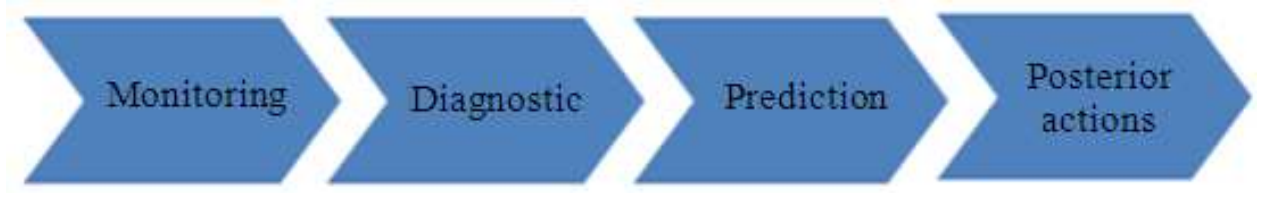

Fig. 1. Summary of the ISO 13381-1: 2004 standard main steps

\subsection{Stochastic Modeling}

The stochastic modeling aims at considering some influent parameters as random variables and hence, the Paris' law becomes stochastic crack propagation law. From data provided from previous diagnostic analysis (Fig. 1), it is possible to consider the initial crack length $\mathrm{a}_{0}$ as the main random variable where the second variable is the stress loading $\sigma$. Many other parameters can be also considered random and the prognostic model can be expressed by the following general function:

$\mathrm{D}(\mathrm{a})=\mathrm{P}_{\mathrm{rog}}(\mathrm{a})=\mathrm{fct}\left(\mathrm{a}_{0}, \sigma\right.$, thickness $\mathrm{e}$, dimensions $\left., \mathrm{C}, \mathrm{m}, \ldots\right)$

The degradation indicator $\mathrm{D}$ variant from 0 to 1 provides instantaneously the Remaining Useful Lifetime (RUL) expressed by time, or cycle, or distance, depending on the type of device concerned. A probabilization of basic parameters leads to a probabilistic trajectory $\tilde{D}(\mathrm{a})$.

All previously mentioned parameters are affected by some probability of realization that influences the resulting RUL deduced from $\mathrm{D}(\mathrm{a})$. Contrary to the deterministic-based prognosis, the RULs concluded in stochastic-based prognosis are related to probabilistic aspect. As the estimated RUL is no longer deterministic, it is affected by some risk percentage in order to be realized.

These relevant basic parameters must be modeled stochastically using a convenient well known probability distribution laws. For example, the initial crack length $a_{0}$ is modeled by either a Normal or LogNormal distribution, the loading $\sigma$ is modeled by a Normal distribution.

\subsection{Stochastic Basic Parameters}

Here a Probability Density Function (PDF) of initial crack length $\mathrm{a}_{0}$ that follows a Log-Normal distribution is considered, then Equation 3:

$$
\mathrm{f}_{0}\left(\mathrm{a}_{0}\right)=\frac{1}{\mathrm{a}_{0} \cdot \xi \cdot \sqrt{2 \cdot \pi}} \cdot \exp \left[-\frac{1}{2 \cdot \xi^{2}}\left(\operatorname{Ln}\left(\mathrm{a}_{0}\right)-\lambda\right)^{2}\right]
$$

With:

$\xi=$ The standard deviation of the variable $\operatorname{Ln}\left(\mathrm{a}_{0}\right)$ which is the equivalent Normal distribution

$\lambda=$ The mean of the variable $\operatorname{Ln}\left(\mathrm{a}_{0}\right)$

Expectation of $\mathrm{a}_{0}$ :

$$
\mathrm{E}\left(\mathrm{a}_{0}\right)=\exp \left[\lambda+\xi^{2} / 2\right]
$$

Variance of $\mathrm{a}_{0}$ :

$$
\mathrm{V}\left(\mathrm{a}_{0}\right)=\exp \left[2 \lambda+\xi^{2}\right] \times\left(\exp \left[\xi^{2}\right]-1\right)
$$

Inversely, one can also write:

$$
\begin{aligned}
& \lambda=\operatorname{Ln}\left[\mathrm{E}\left(\mathrm{a}_{0}\right)\right]-\frac{1}{2} \operatorname{Ln}\left(1+\frac{\mathrm{V}\left(\mathrm{a}_{0}\right)}{\mathrm{E}\left(\mathrm{a}_{0}\right)^{2}}\right) \\
& \xi^{2}=\operatorname{Ln}\left(1+\frac{\mathrm{V}\left(\mathrm{a}_{0}\right)}{\mathrm{E}\left(\mathrm{a}_{0}\right)^{2}}\right) \Rightarrow \xi=\sqrt{\operatorname{Ln}\left(1+\frac{\mathrm{V}\left(\mathrm{a}_{0}\right)}{\mathrm{E}\left(\mathrm{a}_{0}\right)^{2}}\right)}
\end{aligned}
$$

The limit value of crack length $\left(\mathrm{a}_{\mathrm{C}}\right)$ is fixed when the number of cycles reaches the critical value $\left(\mathrm{N}_{\mathrm{C}}\right)$ starting from an initial state $\mathrm{N}_{0}$ (Fig. 2). The probability of fatigue failure is given by:

$$
\mathrm{P}_{\mathrm{rob}}\left(\mathrm{a}_{\mathrm{N}}>\mathrm{a}_{\mathrm{C}}\right)=\int_{\mathrm{a}_{\mathrm{C}}}^{\infty} \mathrm{f}_{\mathrm{N}}\left(\mathrm{a}_{\mathrm{N}}\right) d \mathrm{a}_{\mathrm{N}}
$$

where, $\mathrm{f}_{\mathrm{N}}\left(\mathrm{a}_{\mathrm{N}}\right)$ is the PDF of the crack width $\mathrm{a}(\mathrm{N})$ at cycle $\mathrm{N}$.

It can be assumed that $\mathrm{a}_{\mathrm{C}}=\mathrm{e} / 8$ (Luo et al., 2003), where e and $\ell$ are respectively the device dimension in the crack direction and the perpendicular dimension to the crack direction (Fig. 3). $\Delta \mathrm{a}_{\mathrm{N}}$ is the crack length increment due to a loading cycle $\mathrm{dN}$.

\subsection{PDF of Crack Length $a_{N}$ at Loading Cycle $N$}

From Paris' law we can deduce Equation 4:

$$
\frac{\mathrm{da}}{\mathrm{dN}}=\mathrm{C} \cdot[\Delta \mathrm{K}(\mathrm{a})]^{\mathrm{m}} \Rightarrow \frac{\mathrm{da}}{[\Delta \mathrm{K}(\mathrm{a})]^{\mathrm{m}}}=\mathrm{C} \cdot \mathrm{dN}
$$


Abdo Abou Jaoude and Khaled El-Tawil / American Journal of Engineering and Applied Sciences 6 (2): 145-160, 2013

\section{Fracture}

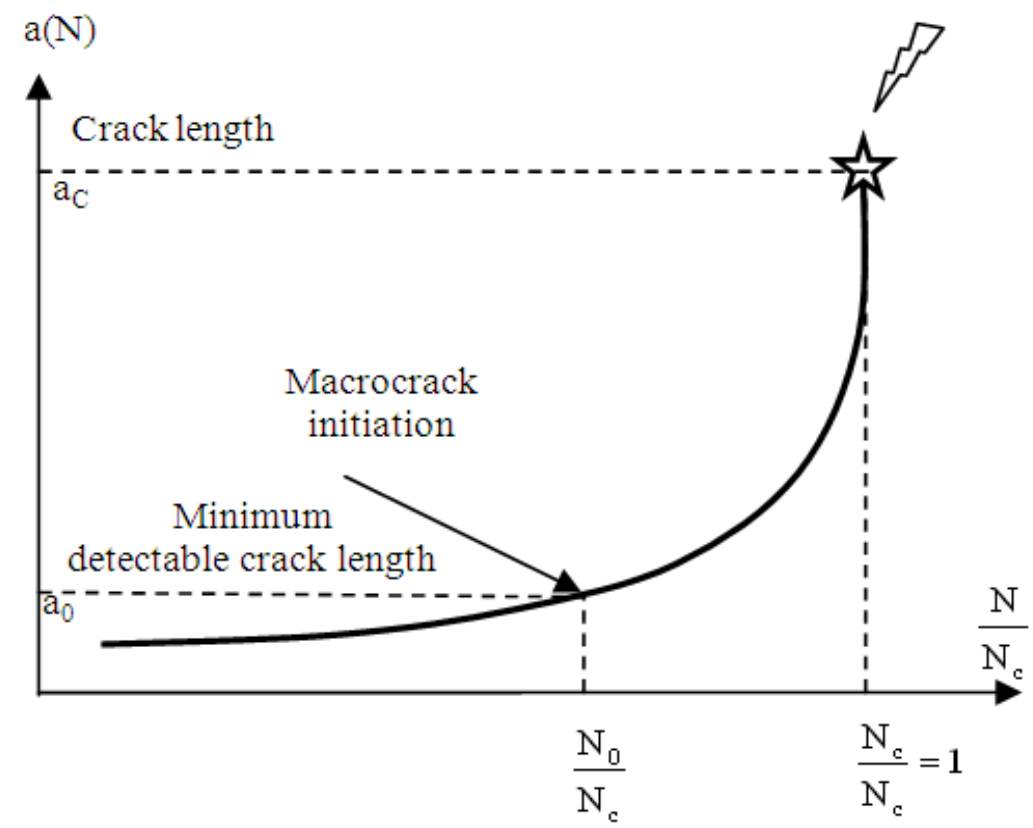

Fig. 2. Pre-Crack fatigue damage

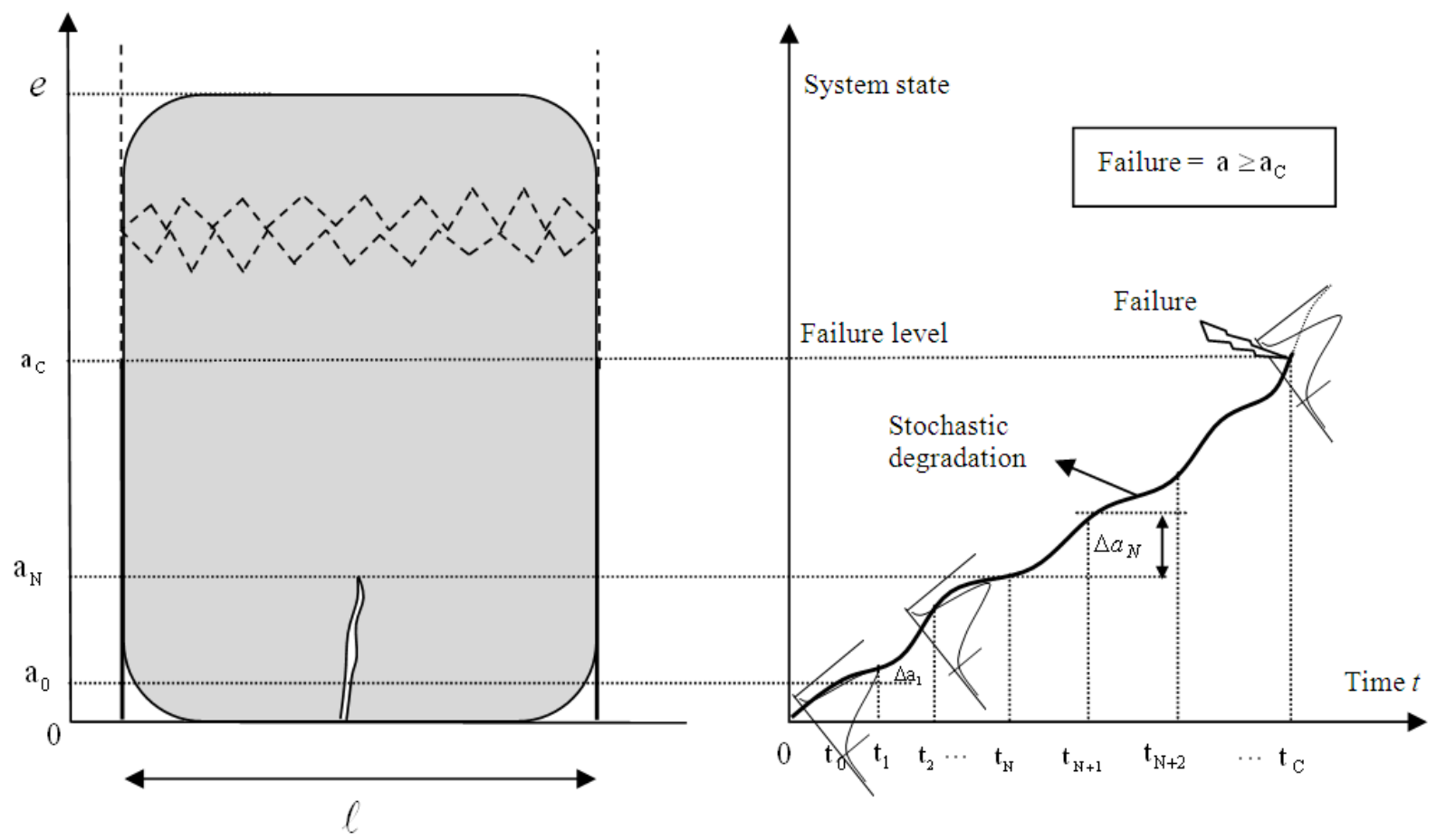

Fig. 3. Probabilistic crack width growth 
Where:

$$
\Delta \mathrm{K}(\mathrm{a})=\mathrm{Y}(\mathrm{a}) \cdot \Delta \sigma \cdot \sqrt{\pi \cdot \mathrm{a}}
$$

If we integrate the two sides between initial state $\mathrm{N}_{0}$ and an arbitrary state N, we get Equation 5:

$$
\begin{aligned}
& \int_{a_{0}}^{a_{N}} \frac{d a}{[\Delta K(a)]^{m}}=\int_{N_{0}}^{N} C \cdot d N \quad ; \quad\left(N_{0}=0\right) \Rightarrow \\
& \int_{a_{0}}^{a_{N}} \frac{d a}{[\Delta K(a)]^{m}}=\int_{a_{0}}^{a_{N}} \frac{d a}{[Y \cdot \Delta \sigma \cdot \sqrt{\pi \cdot a}]^{m}} \\
& =\frac{1}{Y^{m} \cdot(\Delta \sigma)^{m} \cdot \pi^{m / 2}} \int_{a_{0}}^{a_{N}} \frac{d a}{a^{m / 2}}
\end{aligned}
$$

From (4) and (5), we get the following Equation 6-7:

$\Rightarrow \mathrm{a}_{\mathrm{N}}=\left[\mathrm{a}_{0}^{1-\mathrm{m} / 2}+\text { N.C. }\left(1-\frac{\mathrm{m}}{2}\right) \cdot(\mathrm{Y} \cdot \Delta \sigma \cdot \sqrt{\pi})^{\mathrm{m}}\right]^{\frac{2}{2-\mathrm{m}}}$

And:

$$
a_{0}=\left[a_{\mathrm{N}}^{1-\mathrm{m} / 2}-\mathrm{N} \cdot C \cdot\left(1-\frac{\mathrm{m}}{2}\right) \cdot(\mathrm{Y} \cdot \Delta \sigma \cdot \sqrt{\pi})^{\mathrm{m}}\right]^{\frac{2}{2-\mathrm{m}}}
$$

As: $a_{0} \leq a_{N} \leq a_{C}$, then, if we have the PDF of $a_{0}$ : $\mathrm{f}_{0}\left(\mathrm{a}_{0}\right)$, thus we can deduce the PDF of $\mathrm{a}_{\mathrm{N}}$ and $\mathrm{a}_{\mathrm{C}}$ as follows:

$$
\mathrm{f}_{0}\left(\mathrm{a}_{0}\right) \underset{\text { Jacobian }}{\longrightarrow} \quad \mathrm{f}_{\mathrm{N}}\left(\mathrm{a}_{\mathrm{N}}\right) \longrightarrow \mathrm{f}_{\mathrm{C}}\left(\mathrm{a}_{\mathrm{C}}\right)
$$

Initial state $\left(\mathrm{N}_{0}=0\right)$ Arbitrary state $(\mathrm{N})$ Critical (final) state $\left(\mathrm{N}_{\mathrm{C}}\right)$

Then, the following transformation can be given Equation 8:

$$
\mathrm{f}_{\mathrm{N}}\left(\mathrm{a}_{\mathrm{N}}\right)=\mathrm{f}_{0}\left(\mathrm{a}_{0}\right) \times|\mathrm{J}|=\mathrm{f}_{0}\left(\mathrm{a}_{0}\right) \times\left|\frac{\mathrm{da}_{0}}{\mathrm{da}_{\mathrm{N}}}\right|
$$

with the Jacobian $\mathrm{J}=\frac{\mathrm{da}_{0}}{\mathrm{da}_{\mathrm{N}}}$ Equation 7-12:

$$
\mathrm{f}_{0}\left(\mathrm{a}_{0}\right)=\mathrm{f}_{0}\left[\left[\mathrm{a}_{\mathrm{N}}^{1-\mathrm{m} / 2}-\text { N.C. }\left(1-\frac{\mathrm{m}}{2}\right)(\mathrm{Y} \cdot \Delta \sigma \cdot \sqrt{\pi})^{\mathrm{m}}\right]^{\frac{2}{2-\mathrm{m}}}\right]
$$

Let:

Science Publications

$$
\beta=1-\frac{m}{2} \Rightarrow m=2(1-\beta)
$$

And:

$$
\begin{array}{r}
\frac{\mathrm{m}}{2-\mathrm{m}}=\frac{1-\beta}{\beta} \text { and } \frac{2}{2-\mathrm{m}}=\frac{1}{\beta} \\
\Rightarrow \mathrm{f}_{0}\left(\mathrm{a}_{0}\right)=\mathrm{f}_{0}\left[\left[\mathrm{a}_{\mathrm{N}}^{\beta}-\mathrm{N} \cdot \mathrm{C} \cdot \beta \cdot(Y \cdot \Delta \sigma \cdot \sqrt{\pi})^{2(1-\beta)}\right]^{\frac{1}{\beta}}\right] \\
\Rightarrow \mathrm{f}_{0}\left(\mathrm{a}_{0}\right)=\mathrm{f}_{0}\left[\left(\mathrm{a}_{\mathrm{N}}^{\beta}-\mathrm{N} \cdot \mathrm{A}\right)^{\frac{1}{\beta}}\right]
\end{array}
$$

Where:

$$
\mathrm{A}=\mathrm{C} \cdot \beta \cdot(\mathrm{Y} \cdot \Delta \sigma \cdot \sqrt{\pi})^{2(1-\beta)}
$$

Then:

$$
\frac{\mathrm{da}_{0}}{\mathrm{da}_{\mathrm{N}}}=\frac{\mathrm{d}}{\mathrm{da}}\left[\left(\mathrm{a}_{\mathrm{N}}^{\beta}-\mathrm{N} \cdot C \cdot \beta \cdot(\mathrm{Y} \cdot \Delta \sigma \cdot \sqrt{\pi})^{2(1-\beta)}\right)^{\frac{1}{\beta}}\right]
$$

Therefore, the Jacobian is given by Equation 13:

$$
\frac{d a_{0}}{d a_{N}}=a_{N}^{\beta-1} \times\left(a_{N}^{\beta}-N . A\right)^{\frac{1-\beta}{\beta}}
$$

From Equation (8) and (11), the PDF of $\mathrm{a}_{\mathrm{N}}$ is given as follows Equation 14:

$$
\mathrm{f}_{\mathrm{N}}\left(\mathrm{a}_{\mathrm{N}}\right)=\mathrm{f}_{0}\left[\left(\mathrm{a}_{\mathrm{N}}^{\beta}-\mathrm{N} \cdot \mathrm{A}\right)^{\frac{1}{\beta}}\right] \times\left|\mathrm{a}_{\mathrm{N}}^{(\beta-1)} \cdot\left(\mathrm{a}_{\mathrm{N}}^{\beta}-\mathrm{N} \cdot \mathrm{A}\right)^{\frac{1-\beta}{\beta}}\right|
$$

\subsection{PDF of the Initial Damage $D_{0}$}

The relationship between the initial crack length $a_{0}$ and the initial damage $\mathrm{D}_{0}$ is as follows Equation 15-16:

$$
\mathrm{D}_{0}=\frac{\mathrm{a}_{0}}{\mathrm{a}_{\mathrm{C}}-\mathrm{a}_{0}} \Rightarrow \mathrm{a}_{0}=\frac{\mathrm{a}_{\mathrm{C}} \mathrm{D}_{0}}{1+\mathrm{D}_{0}}
$$

The probabilistic transformation theory gives:

$$
\mathrm{f}_{0}\left(\mathrm{D}_{0}\right)=\mathrm{f}_{0}\left(\mathrm{a}_{0}\right) \times\left|\frac{\mathrm{da}_{0}}{\mathrm{dD}_{0}}\right|
$$




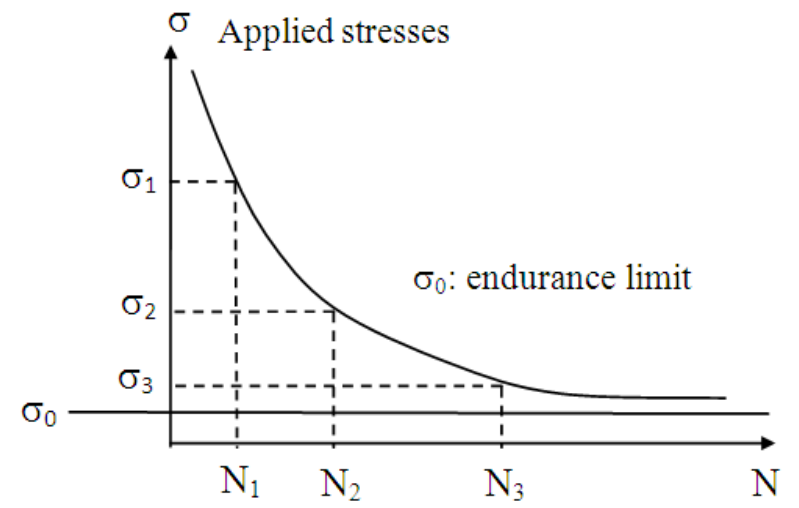

Fig. 4. WÖhler curve of fatigue

As:

$$
\begin{array}{r}
\frac{\mathrm{da}_{0}}{\mathrm{dD}_{0}}=\frac{\mathrm{a}_{\mathrm{C}}}{\left(1+\mathrm{D}_{0}\right)^{2}} \geq 0 \\
\Rightarrow \mathrm{f}_{0}\left(\mathrm{D}_{0}\right)=\mathrm{f}_{0}\left(\mathrm{a}_{0}\right) \times \frac{\mathrm{a}_{\mathrm{C}}}{\left(1+\mathrm{D}_{0}\right)^{2}}
\end{array}
$$

If the proposed law for $\mathrm{a}_{0}$ is Log-Normal, then the law of $\mathrm{D}_{0}$ is also Log-Normal with the following PDF:

$$
\mathrm{f}_{0}\left(\mathrm{D}_{0}\right)=\frac{1}{\mathrm{a}_{0} \cdot \xi \sqrt{2 \cdot \pi}} \exp \left[-\frac{1}{2 \cdot \xi^{2}}\left(\operatorname{Ln}\left(\mathrm{a}_{0}\right)-\lambda\right)^{2}\right] \times \frac{\mathrm{a}_{\mathrm{C}}}{\left(1+\mathrm{D}_{0}\right)^{2}}
$$

As:

$$
\mathrm{a}_{0}=\frac{\mathrm{a}_{\mathrm{C}} \mathrm{D}_{0}}{1+\mathrm{D}_{0}} \text { and } \mathrm{a}_{\mathrm{C}}=\mathrm{e} / 8
$$

Then, we can write the PDF as follows Equation 17:

$$
\mathrm{f}_{0}\left(\mathrm{D}_{0}\right)=\frac{1}{\xi \sqrt{2 \cdot \pi}} \exp \left[-\frac{1}{2 \cdot \xi^{2}}(\operatorname{Ln}[\mathrm{G}]-\lambda)^{2}\right] \times \frac{1}{\mathrm{~F}}
$$

With:

$$
\mathrm{G}=\frac{\mathrm{e} \mathrm{D}_{0}}{8\left(1+\mathrm{D}_{0}\right)} \text { and }: \mathrm{F}=\mathrm{D}_{0}\left(1+\mathrm{D}_{0}\right)
$$

\subsection{Equation of the Stochastic-Based Prognostic}

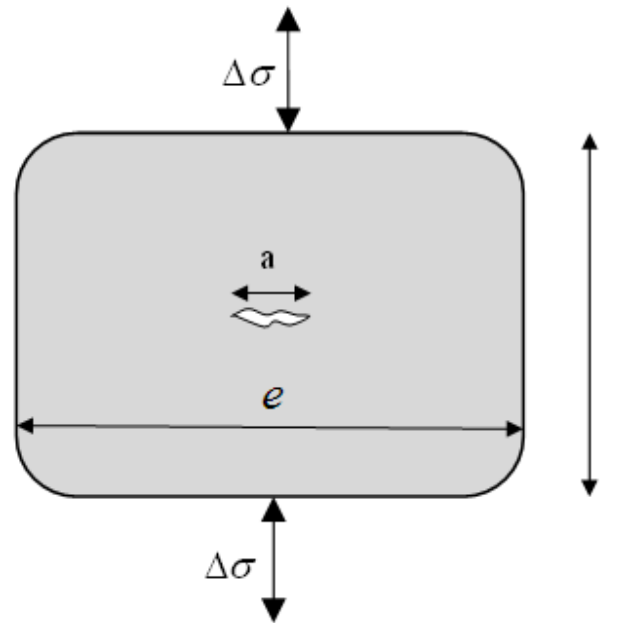

Fig. 5. Critical crack length "a" perpendicular to stress loading

The stress range in fatigue is governed by the WÖhler curve (Lemaitre and Chaboche, 1994) (Fig. 4). The transversal crack is critical when it is normal to the stress loading $\sigma$ (Fig. 5).

In case of pipes of thickness e and radius $\mathrm{R}$, the stress ranges $\Delta \sigma$ are created by the applied internal pressure; hence, the following relation gives the critical hoop stress range $\Delta \sigma_{\theta}$ in terms of pressure range $\Delta \mathrm{P}$ from the mechanics of materials and shell theory (Timoshenko and Woinowsky-Krieger, 1959) (Fig. 5 and 6) Equation 18:

$$
\Delta \sigma_{\theta}=2 . \Delta \sigma_{\mathrm{L}}=\frac{\Delta \mathrm{P} \cdot \mathrm{R}}{\mathrm{e}}
$$

The simulation of internal pressure following a Triangular law generates a sample of stress ranges $\Delta \sigma$ following the same Triangular law.

From Equation (4), where:

$\Delta \mathrm{K}_{\mathrm{I}}(\mathrm{a})$

is the stress intensity factor (Timashev et al., 2005) and:

$$
\mathrm{Y}(\mathrm{a})=0.6 \times \frac{1+2(\mathrm{a} / \mathrm{e})}{(1-\mathrm{a} / \mathrm{e})^{\frac{3}{2}}}
$$

is the geometric function:

$$
\Rightarrow \Delta \mathrm{K}_{\mathrm{I}}(\mathrm{a})=0.6 \times \frac{1+2(\mathrm{a} / \mathrm{e})}{(1-\mathrm{a} / \mathrm{e})^{\frac{3}{2}}} \times \sqrt{\pi \cdot \mathrm{a}} \times \frac{\Delta \mathrm{P} \cdot \mathrm{R}}{\mathrm{e}}=\sqrt[m]{\frac{\mathrm{da}}{\mathrm{C} . \mathrm{dN}}}
$$




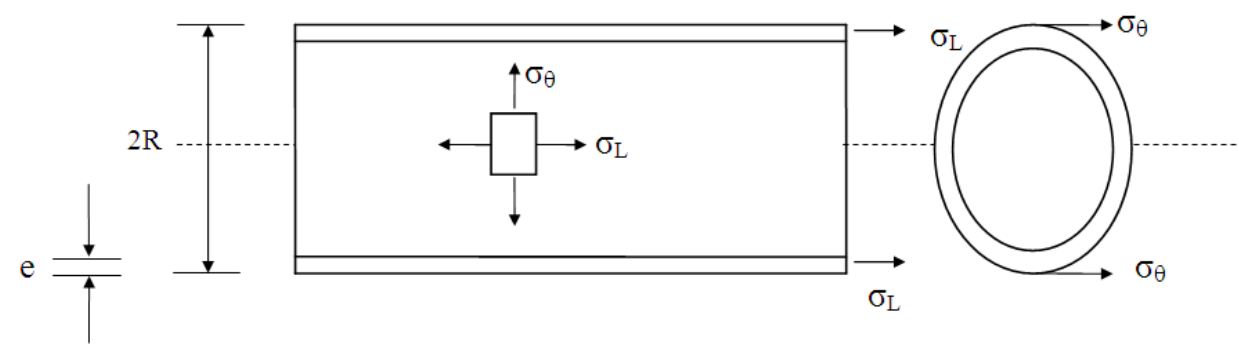

Fig. 6. Stresses in cylindrical pipelines

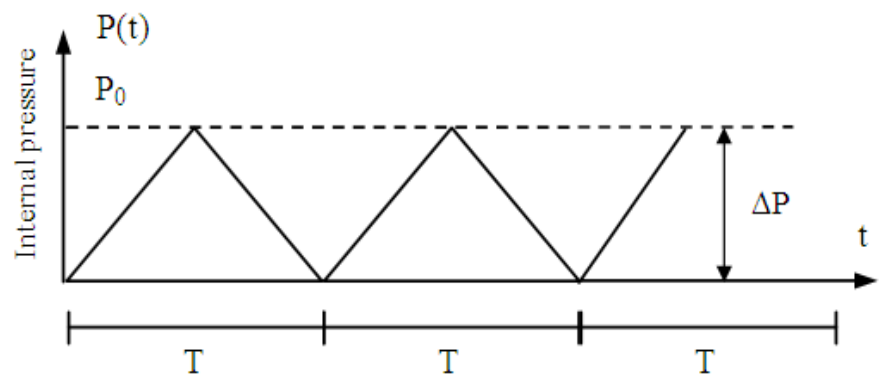

Fig. 7. Triangular pressure law

Then, at the end of each one loading cycle $(\mathrm{dN}=1)$ where $\mathrm{i}=\mathrm{N}$, we can write Equation 19:

$0.6 \times \frac{1+2\left(\mathrm{a}_{\mathrm{i}} / \mathrm{e}\right)}{\left(1-\mathrm{a}_{\mathrm{i}} / \mathrm{e}\right)^{\frac{3}{2}}} \times \sqrt{\pi \cdot \mathrm{a}_{\mathrm{i}}} \times \frac{\Delta \mathrm{P}_{\mathrm{i}} \cdot \mathrm{R}}{\mathrm{e}}=\sqrt[m]{\frac{\mathrm{a}_{\mathrm{i}}-\mathrm{a}_{\mathrm{i}-1}}{\mathrm{C}}}$

In earlier work (Abou Jaoude et al., 2010), the degradation evolution is deduced in terms of crack length growth for each cycle $i$ and is cited in Equation (1). Then Equation 20:

$\mathrm{dD}_{\mathrm{i}}=\frac{\mathrm{da}_{\mathrm{i}}}{\mathrm{a}_{\mathrm{C}}-\mathrm{a}_{0}}=\frac{\mathrm{a}_{\mathrm{i}}-\mathrm{a}_{\mathrm{i}-1}}{\mathrm{a}_{\mathrm{C}}-\mathrm{a}_{0}}$

$\Rightarrow \mathrm{a}_{\mathrm{i}}-\mathrm{a}_{\mathrm{i}-1}=\mathrm{dD}_{\mathrm{i}}\left(\mathrm{a}_{\mathrm{C}}-\mathrm{a}_{0}\right)=\mathrm{dD}_{\mathrm{i}}\left(\mathrm{e} / 8-\mathrm{a}_{0}\right)$

Knowing that $1.01 \leq e / \mathrm{a} \leq 10$ and $\mathrm{e} / \mathrm{a}_{\mathrm{C}}=8$.

From Equation (19) and (20) $\left(\Delta \mathrm{P}_{\mathrm{i}}=\mathrm{P}_{\mathrm{i}}-0=\mathrm{P}_{\mathrm{i}}\right.$, refer to Fig. 7) the degradation increment can be given by the following form:

$\mathrm{dD}_{\mathrm{i}}=\frac{\mathrm{C}}{\left(\mathrm{e} / 8-\mathrm{a}_{0}\right)} \times\left(0.6 \times \frac{1+2\left(\mathrm{a}_{\mathrm{i}} / \mathrm{e}\right)}{\left(1-\mathrm{a}_{\mathrm{i}} / \mathrm{e}\right)^{\frac{3}{2}}} \times \sqrt{\pi \mathrm{a}_{\mathrm{i}}} \times \frac{\mathrm{P}_{\mathrm{i}} \cdot \mathrm{R}}{\mathrm{e}}\right)^{\mathrm{m}}$

and $\mathrm{D}_{\mathrm{i}}=\mathrm{D}_{\mathrm{i}-1}+\mathrm{dD}_{\mathrm{i}}$
The previous relation describes the degradation evolution in terms of the following variables: initial crack size $a_{0}$, internal pressure at cycle $i$ which is $P_{i}$ and the current crack size $a_{i}$. This relation represents the stochastic recursive prognostic model as it permits to relate the degradation indicator $D_{i}$ to the basic random variables $\left(\mathrm{a}_{0}, \mathrm{P}_{\mathrm{i}}\right)$.

At each loading cycle $\left(0 \leq \mathrm{i}=\mathrm{N} \leq \mathrm{N}_{\mathrm{C}}\right)$, the degradation indicator $\mathrm{D}_{\mathrm{i}}$ increments of a quantity $\mathrm{dD}_{\mathrm{i}}$ starting from $\mathrm{D}_{0}=0$ till reaching unit value $\left(\mathrm{D}_{\mathrm{C}}=1\right)$ that is the failure state. Equation (21) represents the stochastic degradation state at cycle $i$.

Parameters $\mathrm{C}$ and $\mathrm{m}$ are variables depending on the environment (temperature, humidity, soil action, applied load location, body shape) and the material properties (brittle, ductile plastic, toughness). $\mathrm{C}$ and $\mathrm{m}$ depend on the testing conditions, such as loading ratio $\sigma_{\min } / \sigma_{\max }$, on the geometry and size of the specimen and on the initial crack length. They are evaluated by the mean of experiments in true conditions. For these reasons, these parameters, estimated from experimental measurements, are given by numerical samples and hence they can be taken as random variables with mean and standard deviation values. The influence of these parameters on D is shown very clearly in Equation (21). 


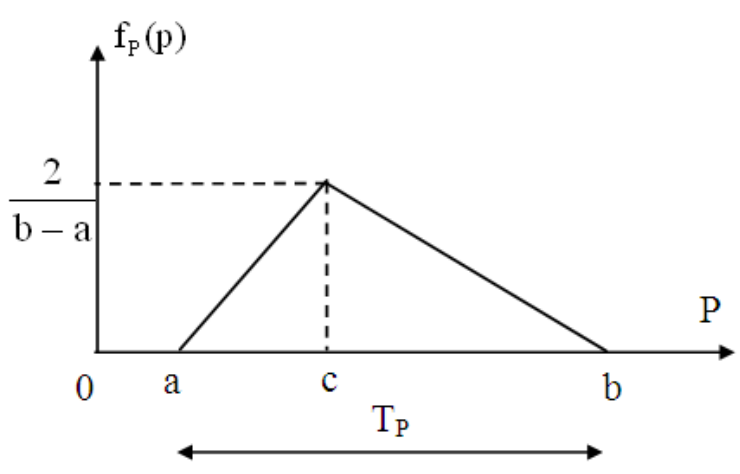

Fig. 8. Triangular PDF function of $P$

In terms of crack width, the degradation is expressed by a crack increment at the end of each loading cycle $(\mathrm{dN}=1)$ by the following recursive relation Equation 22:

$$
\begin{aligned}
& \mathrm{da}_{\mathrm{i}}=\mathrm{C} \cdot\left(\mathrm{Y}\left(\mathrm{a}_{\mathrm{i}}\right) \times \sqrt{\pi \cdot \mathrm{a}_{\mathrm{i}}} \times \Delta \sigma_{\theta}\right)^{\mathrm{m}} \\
& =\mathrm{C} \cdot\left(0.6 \times \frac{1+2\left(\mathrm{a}_{\mathrm{i}} / \mathrm{e}\right)}{\left(1-\mathrm{a}_{\mathrm{i}} / \mathrm{e}\right)^{\frac{3}{2}}} \times \sqrt{\pi \cdot \mathrm{a}_{\mathrm{i}}} \times \frac{\mathrm{P}_{\mathrm{i}} \cdot \mathrm{R}}{\mathrm{e}}\right)^{\mathrm{m}} \\
& \text { and } \mathrm{a}_{\mathrm{i}}=\mathrm{a}_{\mathrm{i}-1}+\mathrm{da}_{\mathrm{i}} \\
& \text { (at } \mathrm{i}=0 \text { then } \mathrm{a}_{\mathrm{i}}=\mathrm{a}_{0}=\text { the initial crack length) }
\end{aligned}
$$

\subsection{Stochastic RUL}

The estimated RUL is then no longer deterministic, but affected by some risk percentage in order to be realized, hence, a bundle of RULs trajectories can be plotted.

Knowing that the RUL function can be expressed by various forms like for example in fatigue mechanics by: crack length $\mathrm{a}_{\mathrm{C}}$, or critical number of cycles $\mathrm{N}_{\mathrm{C}}$, or material tenacity $\mathrm{K}_{\mathrm{IC}}$ depending on the chosen limit states: service limit state $\left(\mathrm{a} \leq \mathrm{a}_{\mathrm{C}}\right)$, or lifetime limit state $\left(\mathrm{N} \leq \mathrm{N}_{\mathrm{C}}\right)$, or strength limit state $\left(\mathrm{K} \leq \mathrm{K}_{\mathrm{IC}}\right)$.

The RUL adopted in this work is the lifetime limit state: $\mathrm{N}_{\mathrm{C}}-\mathrm{N}$ in terms of the number of loading cycles which can be easily converted to time $t$.

\subsection{Generation of Internal Pressure $P$}

In this case the internal pressure is simulated by the Monte Carlo method along a Triangular distribution over one period $\mathrm{T}_{\mathrm{P}}$ (Fig. 8). The choice of this distribution is explained by the fact that during fluid alimentation, the pumping in tubes follows a linear increase and when pumping stops, the internal pressure decreases linearly.

Science Publications
The Triangular law of the internal pressure is given by the following functions.

The Probability Density Function (PDF) of internal pressure $\mathrm{P}$ is Equation 23:

$f_{P}(p)=\left\{\begin{array}{cc}\frac{2(P-a)}{(b-a)(c-a)} & a \leq P \leq c \\ \frac{2(b-P)}{(b-a)(b-c)} & c \leq P \leq b \\ 0 & P<a \text { and } P>b\end{array}\right.$

The Cumulative Density Function (CDF) of internal pressure $\mathrm{P}$ is Equation 24:

$$
F_{P}(p)=\left\{\begin{array}{cc}
0 & P<a \\
\frac{(P-a)^{2}}{(b-a)(c-a)} & a \leq P \leq c \\
1-\frac{(b-P)^{2}}{(b-a)(b-c)} & c<P<b \\
1 & P \geq b
\end{array}\right.
$$

The inverse of the CDF function gives a realization for $\mathrm{P}$ as follows Equation 25:

$$
P=F^{-1}(u)=\left\{\begin{array}{cc}
a+\sqrt{u(b-a)(c-a)} & 0 \leq u \leq \theta \\
b-\sqrt{(1-u)(b-a)(b-c)} & \theta \leq u \leq 1
\end{array}\right.
$$

where, $\mathrm{u}$ is the uniform-based generated value in interval $[0,1]$ :

$$
\text { Take: } \theta=\frac{\mathrm{c}-\mathrm{a}}{\mathrm{b}-\mathrm{a}}
$$

Then, the mean value:

$$
\overline{\mathrm{P}}=\frac{\left(1-\theta^{3}\right)}{6 .(1-\theta)} \approx \frac{\mathrm{a}+\mathrm{c}+\mathrm{b}}{3}
$$

And the variance Equation 26:

$$
\operatorname{var}(\mathrm{P})=\frac{1-\theta \times(1-\theta)}{18}=\left(\frac{\mathrm{b}-\mathrm{a}}{18}\right)^{2} \times\left\{1-\frac{(\mathrm{c}-\mathrm{a}) \cdot(\mathrm{b}-\mathrm{c})}{(\mathrm{b}-\mathrm{a})^{2}}\right\}
$$




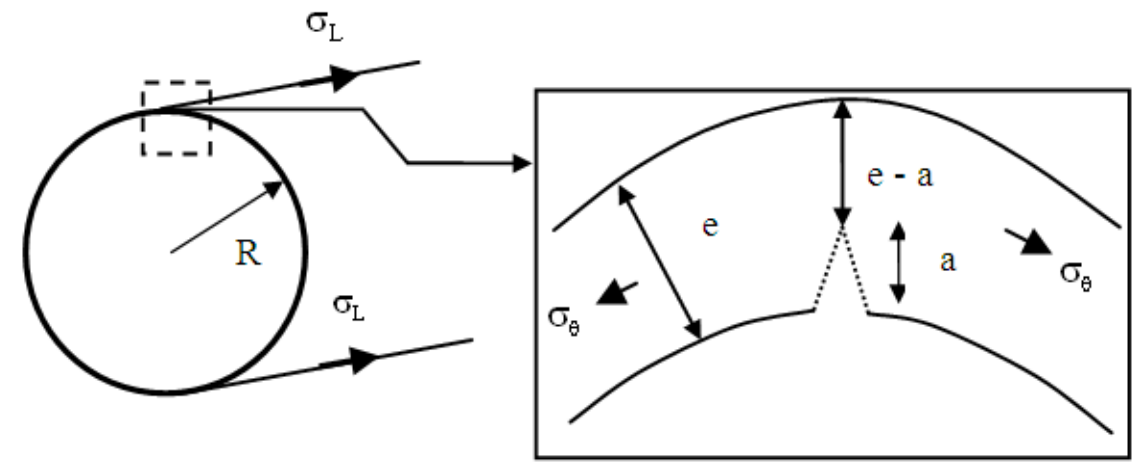

Fig. 9. Cracked pipe section

\subsection{Simulation Procedure}

Here, the simulation of the internal pressure is done using $\mathrm{F}^{-1}(\mathrm{u})$ along one interval $\mathrm{T}_{\mathrm{P}}$ under a Triangular law of mean value $\overline{\mathrm{P}}$ Equation 27:

$\overline{\mathrm{P}} \approx \frac{0+\mathrm{P}_{0}+\mathrm{T}_{\mathrm{P}}}{3}$

For the same initial period, each simulation gives a different realization of the PDF; thus, a new value for $\mathrm{c}=$ $\mathrm{P}_{0}$ is given, keeping always $\mathrm{a}=0$ and $\mathrm{b}=\mathrm{T}_{\mathrm{P}}$.

The following values for the simulation are considered (Fig. 8): $\mathrm{a}=0, \mathrm{~b}=\mathrm{T}_{\mathrm{P}}$ (pressure interval: taken as a percentage of $\mathrm{P}_{0}$ ) and $\mathrm{c}=\mathrm{P}_{0}$ (pressure value: Table 1).

\subsection{Prognostic Study of Pipelines Systems}

Pipelines are principal components in petrochemical industries and systems. They serve to transport oil and natural gas from plants to consumers' sites. Their life prognostic is vital in this industry since their availability has crucial consequences on the exploitation cost. The main failure cause for these systems is the fatigue due to internal pressure-depression variation along the time. Usually, three situations for these pipes exist: unburied, buried and under sea water (offshore pipes). The study of each one of these situations requires data about some physical parameters like: corrosion, soil pressure and friction (for buried pipes), water and atmospheric pressure (for offshore pipes).

The present work is limited to the unburied case. This case (Sukumar et al., 2003) is suitable outside cities between states and countries where they do not intercept any construction or transportation facilities. In this case, the normal service load includes only the internal pressure beside the environmental effects.
Table 1. Three pressure modes

\begin{tabular}{ll}
\hline Pressure mode & $\mathrm{P}_{0}(\mathrm{MPa})$ \\
\hline High (mode 1) & 8 \\
Middle (mode 2) & 5 \\
Low (mode 3) & 3 \\
\hline
\end{tabular}

\subsection{Mechanical Modeling}

The pipes are cylindrical thin tubes since their thickness e to radius ratio $\mathrm{R}$ is (Abou Jaoude et al., 2011b): e/R $\leq 1 / 10$. In this case, the membrane stresses without any bending forces are the circumferential (hoop stress) $\sigma_{\theta}$ and at right angle, the longitudinal (axial stress) $\sigma_{\mathrm{L}}$ given by Equation 28 :

$\sigma_{\theta}=\frac{\mathrm{P} \cdot \mathrm{R}}{\mathrm{e}} ; \quad \sigma_{\mathrm{L}}=\frac{\mathrm{P} \cdot \mathrm{R}}{2 \cdot \mathrm{e}}$

The critical position of cracks is longitudinal which is perpendicular to the direction of maximal stresses $\sigma_{\theta}$. It has a depth (or length) a measured in the direction of tube thickness e (Fig. 9). Generally, it can be considered the following ratio interval: $0.1 \leq \mathrm{a} / \mathrm{e} \leq 0.99$.

Consider a pipe of radius $\mathrm{R}=240 \mathrm{~mm}$ and of thickness $\mathrm{e}=8 \mathrm{~mm}$ transporting natural gas. In this case, the material and environment parameters are $\mathrm{C}=5.2 .10^{-}$ 13 (free air) and $\mathrm{m}=3$ (metal).

\subsection{Simulations of Three Levels of Internal Pressure}

Three maximal levels of $\mathrm{P}=\mathrm{P}_{0}$ are considered (Table 1) with a repetition period $T_{P}$. For each of these levels, a degradation trajectory $\mathrm{D}$ is deduced in term of cycle number $\mathrm{N}$. when $\mathrm{D}$ reaches the unit value, then the corresponding $\mathrm{N}$ is called the lifetime of the pipe that failed by fatigue. 


\subsection{Basic Random Variables}

The generation of the two basic random variables $\left(\mathrm{a}_{0}\right.$ and $\mathrm{P}$ ) is done along the Log-Normal and the Triangular laws respectively.

The initial crack length $\mathrm{a}_{0}$ is simulated along the Log-Normal law with the following parameters:

$$
\mathrm{a}_{0}: \log -\text { Normal law }\left\{\begin{array}{c}
\mathrm{E}\left(\mathrm{a}_{0}\right)=0.2 \mathrm{~mm} \\
\sigma_{\mathrm{a}_{0}}=\sqrt{\operatorname{Var}\left(\mathrm{a}_{0}\right)}=0.0029 \mathrm{~mm}
\end{array}\right.
$$

Then, the equivalent Normal parameters for $\mathrm{a}_{0}$ are:

$$
\lambda=-1.6095 ; \xi=0.014724
$$

The internal pressure is simulated along a Triangular law for three different modes $\mathrm{P}_{0}$ (Table 1).

With mean value:

$$
\overline{\mathrm{P}} \approx \frac{0+\mathrm{P}_{0}+\mathrm{T}_{\mathrm{P}}}{3}
$$
follows:

We can deduce from Equation (26) the variance as

$$
\operatorname{var}(\mathrm{P})=\frac{\left(\mathrm{T}_{\mathrm{P}}\right)^{2}-\left(\mathrm{P}_{0}\right)\left(\mathrm{T}_{\mathrm{P}}-\mathrm{P}_{0}\right)}{18^{2}}
$$

\section{RESULTS}

The Triangular simulation of the pressure inside the unburied pipes and for the 3 modes leads to the applied stress blocks shown in Fig. 10 below. This figure shows that, for the 3 blocks of applied stresses, the randomness is clearly illustrated by the fluctuation values of these stresses with the cycle numbers. The mean values of the 3 blocks are respectively 240, 150 and $90 \mathrm{MPa}$.

The crack width $a(t)$ growth versus time is given in Fig. 11 that shows the width evolution from an initial value $a_{0}$ to the critical value $a_{C}=e / 8$. The crack widths versus time are given in this figure for the 3 modes. They grow from an initial value $\mathrm{a}_{0}=0.2 \mathrm{~mm}$ to the end of life where all curves a(t) reach the critical width $\mathrm{a}_{\mathrm{C}}=\mathrm{e} / 8=1$. The high pressure mode reveals the fastest width increase.

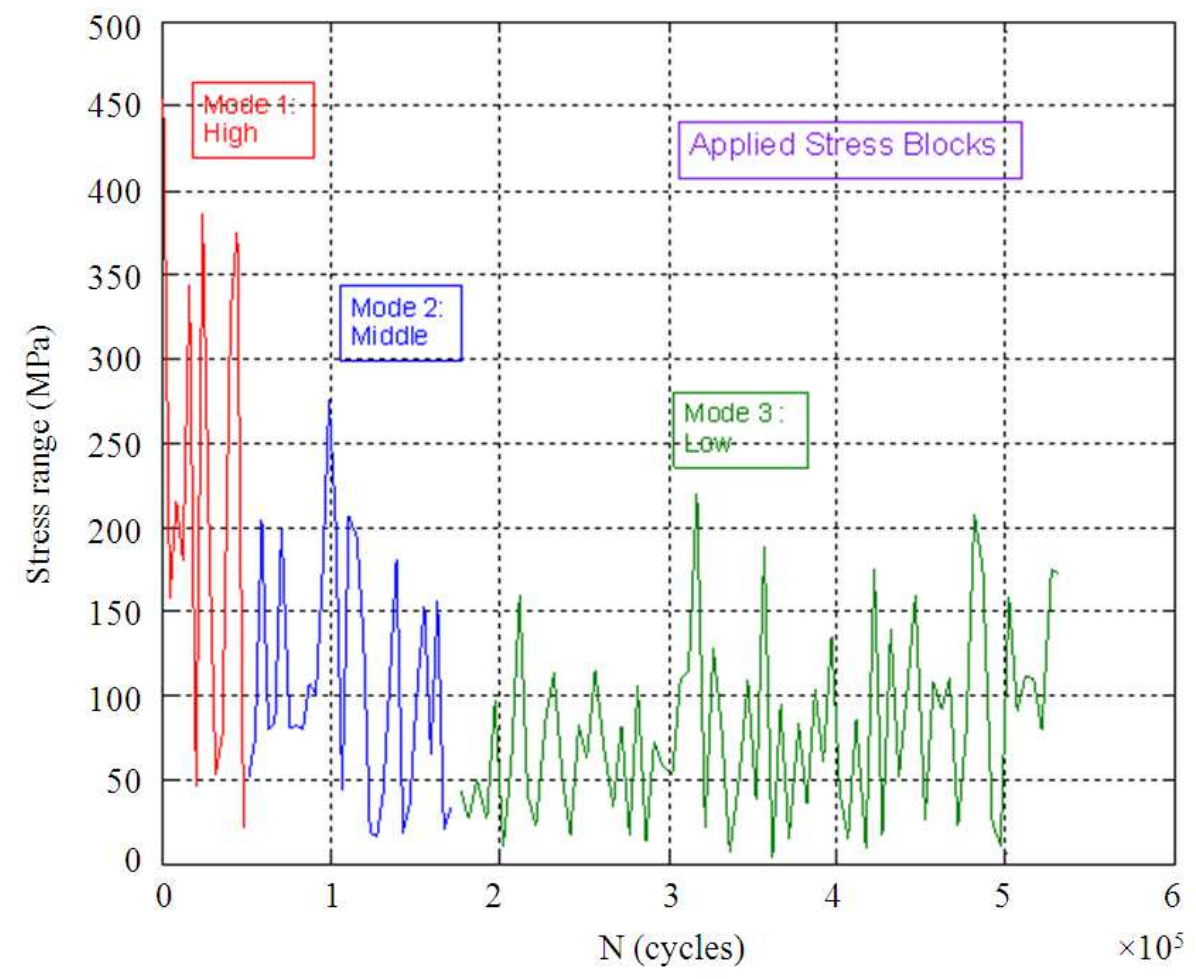

Fig. 10. Applied stress blocks in pipes for 3 modes of pressure 
Abdo Abou Jaoude and Khaled El-Tawil / American Journal of Engineering and Applied Sciences 6 (2): 145-160, 2013

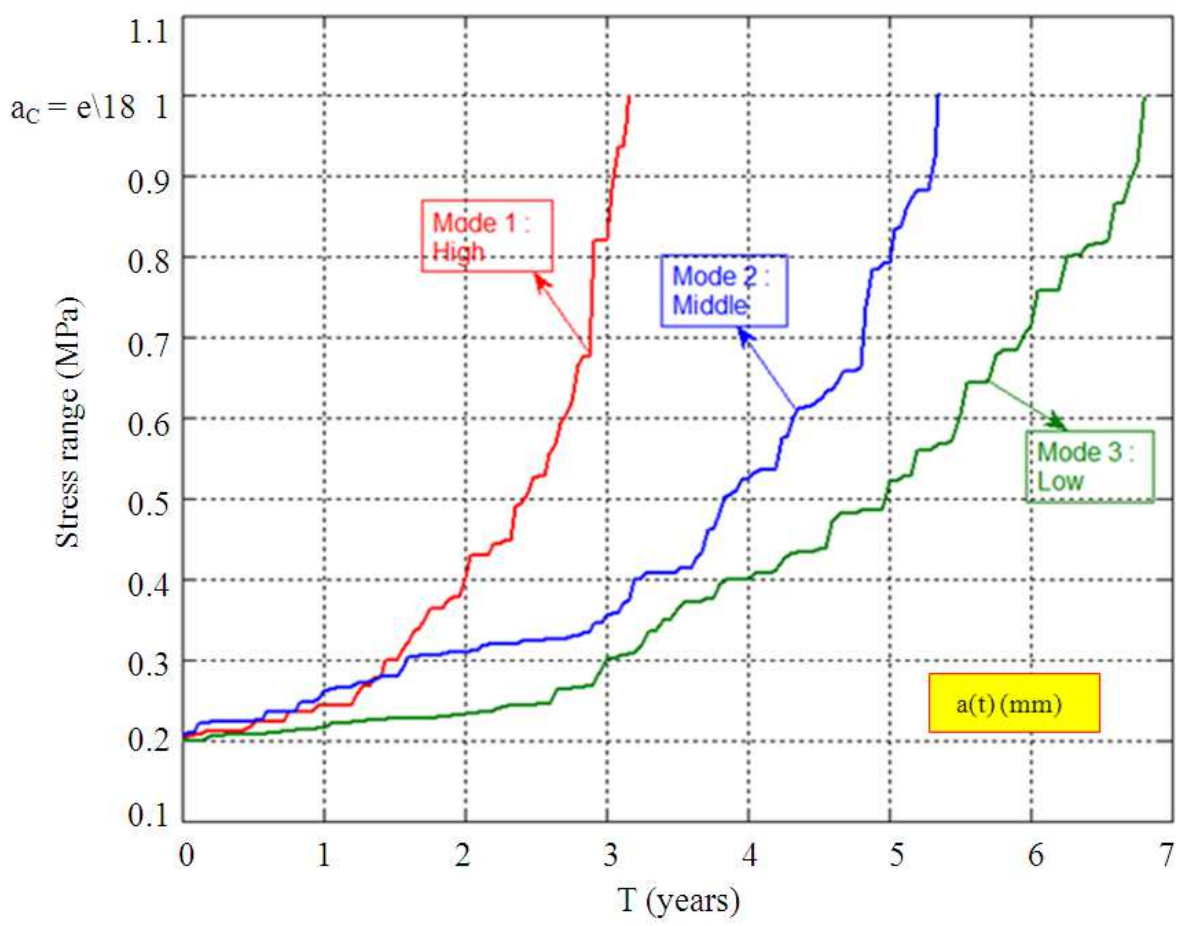

Fig. 11. Crack width evolution with time for 3 modes of pressure

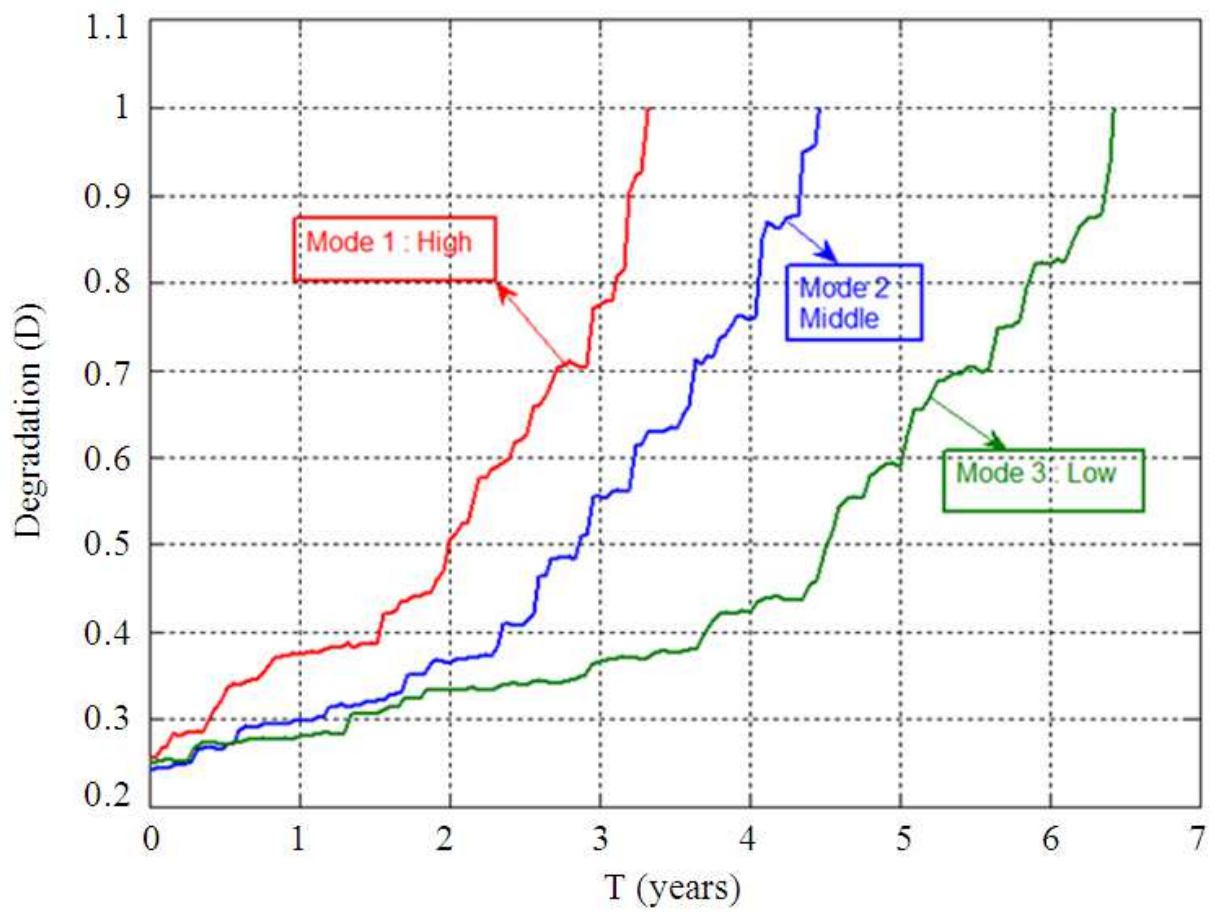

Fig. 12. Pipe degradation evolution for 3 modes of pressure 


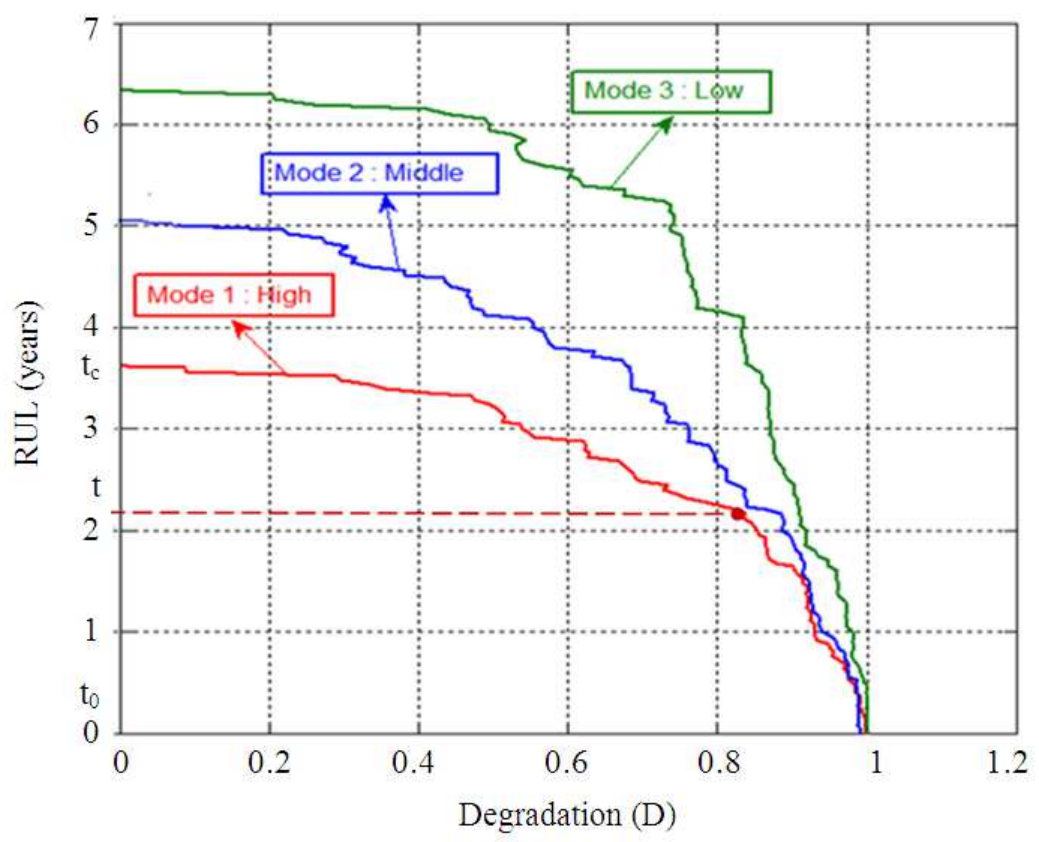

Fig. 13. Pipe RUL evolution for 3 modes of pressure

We should note here that even though "a" and D appear to be identical in the simulation curves, they are different because "a" varies generally from $\mathrm{a}_{0}$ to $\mathrm{a}_{\mathrm{C}}$ (that happens to be here $=1$ since $\mathrm{e}=8 \mathrm{~mm}$ ) whereas $\mathrm{D}$ varies in all cases from 0 to 1 and it is then a more convenient index for damage measurement since it is normalized.

The simulation of the prognostic Equation (21) previously developed permits to draw, for each level of pressure (high, middle, low), the degradation trajectory $\mathrm{D}$ in terms of time $\mathrm{t}$.

The results of degradation trajectory simulations are shown in Fig. 12 below. The degradation indicator D evolves from 0 to 1 (end of its life) and this for each pressure mode. The obtained lifetimes values are verified to be in the range of real lifetimes according to the references (Guan et al., 2010; Xiang and Liu, 2010).

The pipe lifetimes for this case are fixed when D reaches the unit value. They are nearly 3.36 years for mode 1 (high pressure), 4.48 years for mode 2 (middle pressure) and 6.45 years for mode 3 (low pressure).

Conversely, at each instant $t$, the RUL( $t)=t_{c}-t$ (Fig. 13) can be deduced starting from the raw state of the pipe $\operatorname{RUL}\left(\mathrm{t}_{0}\right)=\mathrm{t}_{\mathrm{c}}-\mathrm{t}_{0}$ which gives the entire age of the pipe, till reaching the failure state $(D=1)$ where $\operatorname{RUL}\left(t_{c}\right)$ $=t_{c}-t_{c}=0$ (Fig. 13 for Mode 1: High).

As it can be noticed, these curves are stochastic and the lifetimes deduced from them are also stochastic.
Therefore, we do not have a unique value for the corresponding RUL, but rather a new realization is derived from each simulation and then a mean value of RUL can be inferred.

The stochastic influence can be seen through the variability over the curve realizations of $\tilde{D}(N)$ obtained by several simulations and not from just one realization.

The mean curve $\overline{\mathrm{D}}(\mathrm{N})$ is plotted from the mean value of these realizations. The conservative curves are those that give the maximum values. For each mode, the characteristic value of lifetime can be computed from the mean value, the standard deviation and a certain fractal percentage depending on the risk adopted by specialized decision makers.

\subsection{Flowchart of the Stochastic-Based Linear Prognostic}

A flowchart given in Fig. 14 below summarizes all the executive steps of the proposed model. It is divided into two main parts: the stochastic part where the simulations of variables are done and the damage accumulation part where the measure of degradation $\mathrm{D}$ and crack length a are updated and cumulated after each cycle $\mathrm{N}$. 
Abdo Abou Jaoude and Khaled El-Tawil / American Journal of Engineering and Applied Sciences 6 (2): 145-160, 2013

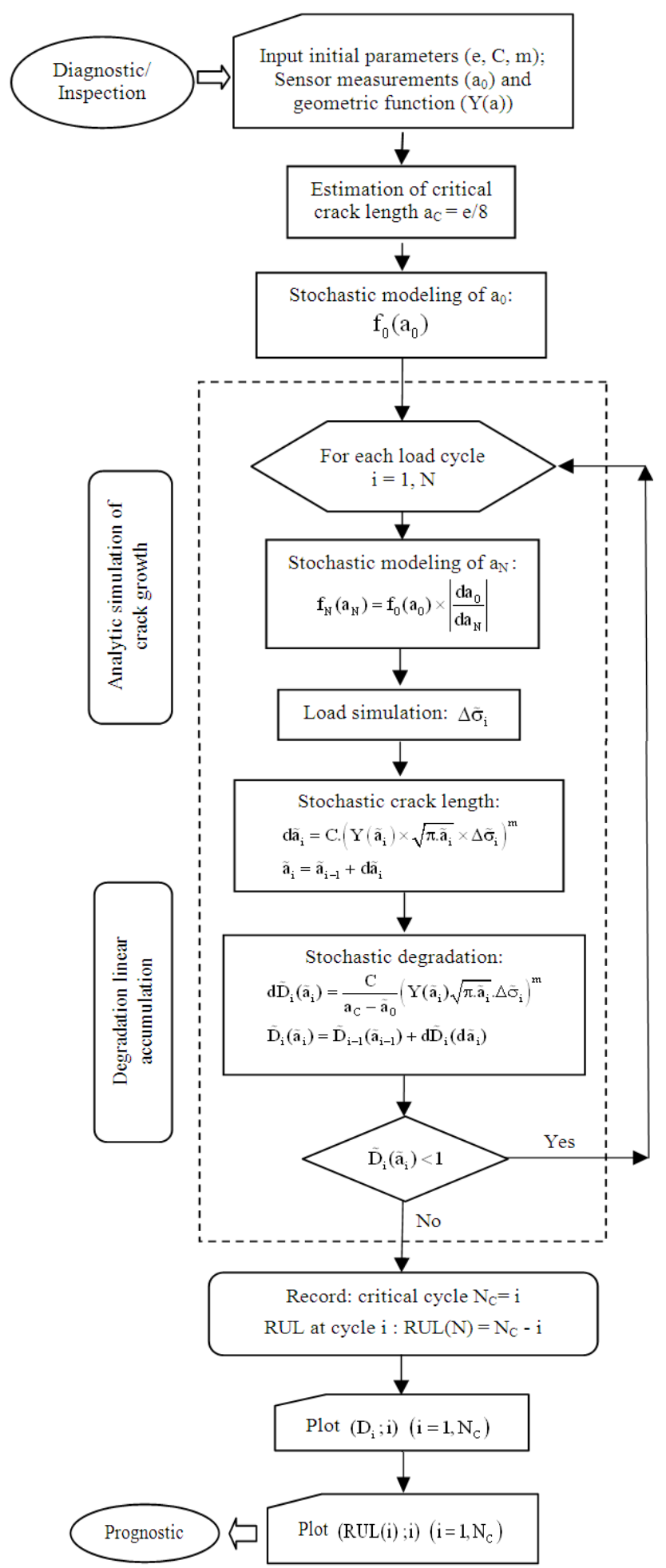

Fig. 14. Flowchart of the proposed model 


\section{CONCLUSION}

A prognostic model is proposed in this work based on the accumulation of damage due to fatigue crack propagation in stochastic conditions. The damage state of the device is measured by a degradation indicator in terms of the number of loading cycles. To show the efficiency of this prognostic model, it is applied to predict the fatigue life of an unburied pipeline under 3 modes of pressure where the initial crack length and the internal pressure are taken random.

The main differences between the degradation measurement $\mathrm{D}$ and the crack length a are: (1) D is normalized (from 0 to 1 ) while a is not generally (from $\mathrm{a}_{0}$ to $\mathrm{a}_{\mathrm{C}}$ ); (2) $\mathrm{D}$ can take into account many damage parameters (corrosion, cracks, deflection, resonance) while a represents only one damage parameter which is the crack length itself.

As a prospective work, it is planned to explore the variability of the stochastic lifetimes in order to deduce a characteristic one attached to some acceptable risk.

\section{REFERENCES}

Abou Jaoude, A., K. El-Tawil, S. Kadry, H. Noura and M. Ouladsine, 2010. Analytic prognostic model for a dynamic system. Int. Rev. Automatic Control, 3: 568-568.

Abou Jaoude, A., K. El-Tawil, S. Kadry, H. Noura and M. Ouladsine, 2011b. Prognostic model for buried tubes. Proceedings of the International Conference on Advanced Research and Applications in Mechanical Engineering, Jun. 1-1, Notre Dame University, pp: 13-15.

Abou Jaoude, A., S. Kadry, K. El-Tawil, H. Noura and M. Ouladsine, 2011a. Analytic prognostic for petrochemical pipelines. J. Mech. Eng. Res., 3: 64-74.

Christodoulou, L. and J.M. Larsen, 2004. Using materials prognosis to maximize the utilization potential of complex mechanical systems. J. Metals, 56: 15-19. DOI: 10.1007/s11837-004-0027-4

Guan, X., R. Jha and Y. Liu, 2010. Trans-dimensional MCMC for fatigue prognosis model determination, updating, and averaging. Proceedings of the Annual Conference of the Prognostic and Health Management Society, (PHMS' 10).

Hudak, Jr. S.J., M.P. Enright, R.C. McClung, H.R. Millwater and A. Sarlashkar et al., 2002. Potential benefits of adding probabilistic damage accumulation to prognosis of turbine engine reliability. SwRI Final Report to AFRL/DARPA.
Inman, D.J., C.R. Farrar, V.L. Junior and V.S. Junior, 2005. Damage Prognosis: For Aerospace, Civil and Mechanical Systems. 1st Edn., John Wiley and Sons, Chichester, ISBN-10: 0470869089, pp: 470.

Jaske, C.E., 2000. Fitness-for-service assessment for pipelines subject to stress-corrosion cracking. Proceedings of the Pipeline Pigging and Integrity Conference, (PPIC' 00).

Lee, J., 2004. Smart products and service systems for ebusiness transformation. Int. J. Technol. Manage., 26: $45-52$.

Lemaitre, J. and J. Chaboche, 1994. Mechanics of Solid Materials. 1st Edn., Cambridge University Press, Cambridge, ISBN-10: 0521477581, pp: 556.

Leverant, G.R., D.L. Littlefield, R.C. McClung, H.R. Millwater and J.Y. Wu, 1977. A probabilistic approach to aircraft turbine rotor material design. Proceedings of the ASME International Gas Turbine and Aeroengine Congress, (IGTAC' 77).

Luo, J., M. Namburu, K. Pattipati, L. Qiao and M. Kawamoto et al., 2003. Model-based prognostic techniques. Proceedings of the IEEE Systems Readiness Technology Conference, Sept. 22-25, IEEE Xplore Press, pp: 330-340. DOI: 10.1109/AUTEST.2003.1243596

Miner, M.A., 1945. Cumulative damage in fatigue. J. Applied Mech., 12: A159-A164.

Moreno, B., J. Zapatero and J. Dominguez, 2003. An experimental analysis of fatigue crack growth under random loading. Int. J. Fatigue, 25: 597-608. DOI: 10.1016/S0142-1123(03)00018-5

Paris, P.C., 1963. A critical analysis of crack propagation laws. Trans. Am. Soc. Mech. Eng., 85: 528-534.

Peysson, F., 2009. Contribution au Pronostic des Systèmes Complexes. Thèse de doctorat, Université d'Aix-Marseille, France.

Sergeeva, T.K. and A.C. Bolotov, 1996. Monitoring of steel condition in main pipelines during their stresscorrosion induced failures. Chem. Oil Machinery.

Sukumar, N., D.L. Chopp and B. Moran, 2003. Extended finite element method and fast marching method for three-dimensional fatigue crack propagation. Eng. Fracture Mech., 70: 29-48. ftp://melmac.sd.ruhr-unibochum.de/X-FEM-SDA/3Dxfem_fatigue-crack.pdf

Timashev, S.A., M.G. Malyukova and L.L. Maltsev, 2005. Updating the assessment of remaining life of pipelines using latest ILI data and the importance sampling method. Science and Engineering Center, Reliability and Resource of Large Machine Systems, Ural Branch, Russian Academy of Sciences, Rotterdam. 
Timoshenko, S. and S. Woinowsky-Krieger, 1959. Theory of Plates and Shells. 2nd Edn., McGrawHill, Auckland, N.Z., pp: 580.

Vachtsevanos, G., F.L. Lewis, M. Roemer, A. Hess and B. Wu, 2006. Intelligent Fault Diagnosis and Prognosis for Engineering Systems. 1st Edn., John Wiley and Sons, Hoboken, N.J., ISBN-10: 047172999X, pp: 456.
Xiang, Y. and Y. Liu, 2010. Efficient probabilistic methods for real-time fatigue damage prognosis. Proceedings of the Annual Conference of the Prognostic and Health Management Society, Aug. 26-26, PHM Society, pp: 1-12.

Yang, J.N. and S.D. Manning, 2003. A simple second order approximation for stochastic crack growth analysis. Probabilistic Eng. Mech., 18: 107-118. 